\title{
Application and Empirical Investigation of New MOOC Teaching System in Computer Application Course
}

\author{
http://dx.doi.org/10.3991/ijet.v11i05.5696 \\ Zhenhua Ji \\ Yiwu Industrial and Commercial College, Yiwu, Zhejiang, China
}

\begin{abstract}
- this paper summarized the characteristics of the traditional computer teaching, through analysis, it pointed out the deficiencies of the traditional computer teaching in the process. This paper introduced MOOC(massive open online teaching), explained its merits in teaching with details. Taking computer application course in vocational college as experimental subject, study on effect of multimedia MOOC teaching system on the course were conducted. Study shows that multimedia MOOC teaching systems can greatly improve students ' enthusiasm for computer learning, it can improve students ' learning efficiency with online interact learning and personalized learning, it also increases application efficiency of educational resources. Multimedia MOOC systems is more adaptive to the needs of our time, but there are also some weakness, this paper put forward improvement suggestions for the system hoping to contribute a little for wide application of multimedia MOOC system.
\end{abstract}

Index Terms-Massive Open Online Course, Multimedia, MOOC, Computer Application Course

\section{INTRODUCTION}

As the rapid development of science and technology, in particular the development of internet technology, all sectors and all aspects are or will inevitably be affected by the Internet technologies, following network and information has become one of the general trend of our time. In recent years, MOOC experienced growth from infancy to rapid development. It has gradually generated an unprecedented impact on traditional education. MOOC with its sharing mode of open, large-scale, free high end education resources enables more fair and efficient distribution of education resources, thus greatly promoted the deeper transformation of traditional education and rapid development of multimedia teaching technology [1]. "MOOC" is an online curriculum development model, it's emerged from the resources release and learning management system in the past, it combined the old learning management system with more open networks resources and emerged as a new curriculum development model [2]. (MOOC): "M" represents Massive, unlike only dozens or hundreds students in traditional courses, a MOOC course usually has tens thousands of people, up to 160,000 people; second letter "O" represents Open, it is interest oriented, whoever want to learn, despite the nationality, can register and $\log$ in with just an email address; the third letter "O" represents Online, learning online does not restrained by geological locations, it spares people with travel; the fourth letter " $\mathrm{C}$ " represents the Course, is the meaning of course [3].
Influence of MOOC on traditional teaching is omnidirectional, it causes revolution on education model, through MOOC teaching experiment, Al-Atabi and DeBoer thought that MOOC is a suitable platform to teach entrepreneurship as it provides tools to enable students' collaborative learning as well as improve effective key entrepreneurial aspects such as opportunity recognition and resource acquisition [4]. MOOC has relatively large impact on the teaching of computer major. Research teams such as Fidalgo Blanco á, conducted an improved MOOC teaching practice in three Spanish Universities. The proposed methodology integrates the learning strategies of $\mathrm{x}$ MOOCs and c MOOCs with adaption and knowledge management capabilities, which obtained recognition and support from users [5]. Related researchers raised that the proposed methodology integrates the learning strategies of $\mathrm{x}$ MOOCs and $\mathrm{c}$ MOOCs with adaption and knowledge management capabilities [6]. Viswanathan thought that with the experience of attending MOOC, the author highlighted how the course widened her knowledge of digital learning and she also discussed the relevance of the online courses to teacher development in her article [1].

Computer major primarily includes computer application, networking and information technology, its learning is more practice-oriented [7]. Traditional closed teaching mode of computer major makes training efficiency generally low, traditional teaching mode of computer major makes computer courses learning relatively boring, and due to teachers' leading role in teaching, the teaching efficiency is uneven, distribution of educational resources is not fair enough. In traditional computer teaching, students do not allow necessary communication and reflection, and actual operation capacity obviously is insufficient [8]. $\mathrm{Xu}$ used cloud computing technology in multimedia teaching, proposed construction ideas for usercentric and demand-oriented multimedia teaching resource library aiming to promote learning and creativity as fundamental [9]. Zhu et al. attempted computer course teaching on the EDX MOOC platform and analyzed the designed teaching model and its application. Their experiment results confirmed that MOOC is conducive to teaching computer science, is a modern teaching method that can be easily accepted by students [10]. We can see that, through changing into MOOC teaching mode of computer courses, we can share high quality resources real-time. It makes computer study more intuitive and efficient and can better meet students' individual learning needs.

Innovation of this research is: multimedia MOOC system mainly depends on wireless network signal transmis- 
sion, big capacity wireless network data input and feedback makes system of three modules stably connected, breaking away from weaknesses of multimedia teaching equipment such as insufficient storage capacity or transmission flow limit, making MOOC system efficient and stable to support mass video play. By establishing a new multimedia MOOC system and analysis of its teaching effect in computer teaching application, this paper verified the superiority of this system and did experiments to explore the shortcomings of the system, to provide necessary preparations for further improvement of modern educational technology and large-scale promotion.

\section{MULTIMEDIA MOOC SYSTEM IMPLEMENTATION AND ITS APPLICATION IN COMPUTER TEACHING}

\section{A. Meaning of the multimedia MOOC teaching}

Multimedia MOOC teaching is a new large-scale digital teaching mode and of real-time online sharing of teaching resources based on network and multimedia technology [11]. Multimedia MOOC teaching is student-centered, which promotes students ' individual development through rational allocation of teaching resources, and constantly improve students ' learning interest and learning quality.

\section{B. Multimedia MOOC teaching system}

Multimedia MOOC teaching system consists of three parts: namely the controlling terminal, the master-end terminal and teaching terminal, connected through Wi-Fi, forming a complete multimedia MOOC system, its system is as described in Figure 1.

As shown in Figure 1: control terminal of multimedia MOOC teaching system is mainly composed of input device, video recording device and control port Wi-Fi module. Where the input devices feed in play information from users; video recording device is used to enter additional video information such as the appropriate video and recording info; control port $\mathrm{Wi}-\mathrm{Fi}$ modules are used to transmit video playing information and additional information that is required by the corresponding video. Master-end terminal is mainly composed of UPS, storage equipment and sound video conversion unit. UPS provides uninterrupted power supply for the system operation; storage unit is to store related teaching video; sound video conversion unit is for merging and conversing needed video and the corresponding additional information. Playing video and additional information needs to be achieved through speakers and projector. Teaching terminal is consisted of input devices and teaching Wi-Fi modules, input devices is for users to input feedback, teaching-end wireless network module is for receiving video and additional information and feedback.

Main function of the control terminals is to input related control instructions and video information, the master-end terminal will integrate video information for the broadcast, teaching terminal can play video and feedback information.

Multimedia teaching system usually encounters constraints such as flow limit, signal limit and storage, as shown in Figure 2, multimedia MOOC system built in this paper uses wireless network signal transmission mainly, data input and feedback through big capacity wireless network makes three modules in the system stably connected, enabling the system from restraints such as insufficient storage capacity and transmission flow limit, making MOOC system efficient and stable to support mass video play.

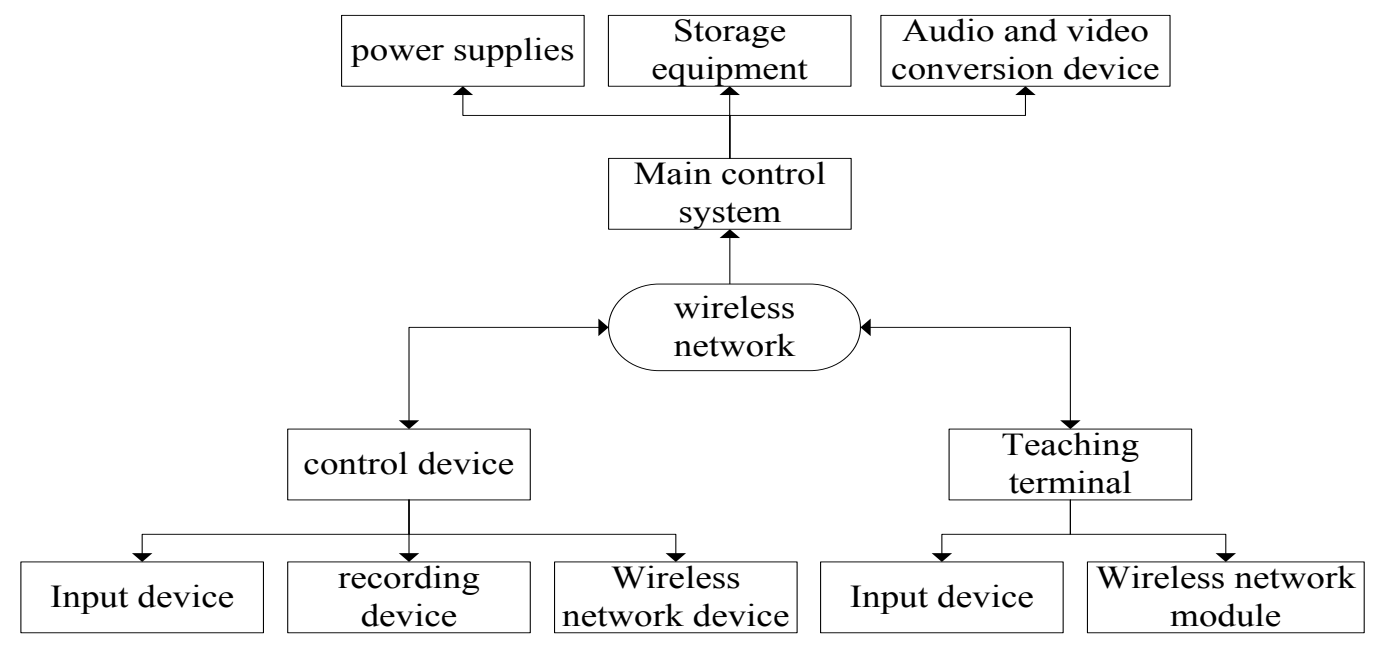

Figure 1. Structure Chart of Multimedia MOOC Teaching System

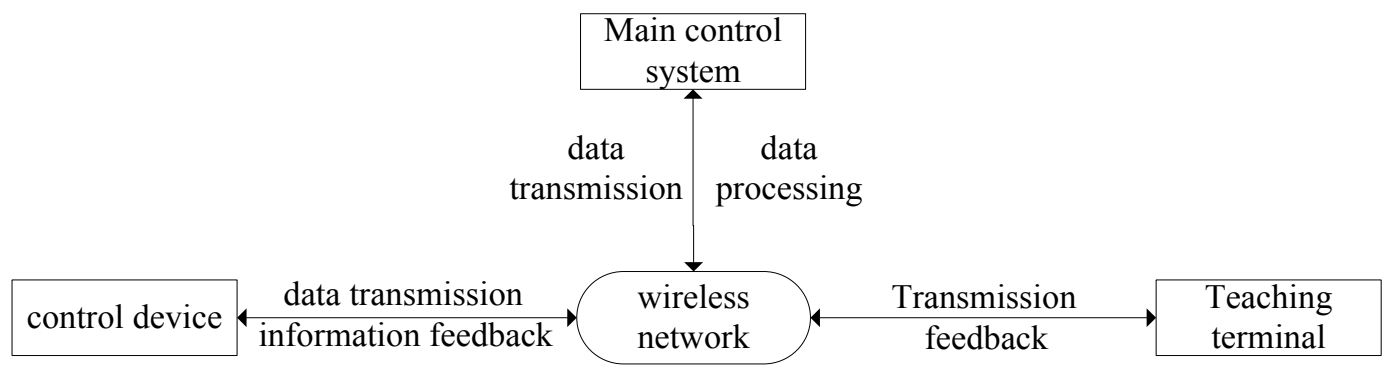

Figure 2. System Connection Diagram 


\section{Operation mode of multimedia MOOC system}

As shown in Figure 3, operation mode of multimedia MOOC system in vocational college is significantly different from the public edX and Coursera. Because of the particularity and openness of school education, teaching resources selected by MOOC system has certain restrictions. The main video resources come from i cloud video resources of the school or other colleges and universities in China, the video has to undergo a rigorous screening to meet the requirements of University teaching. As seen from the figure: the video source is widely available, embodying the superiority of multimedia MOOC teaching.

\section{Multimedia MOOC system interface}

Figure 4 shows the main page of MOOC teaching system, we can see from figure 3 that MOOC teaching system has relatively simple main page. It only has two options: registration and login, student and teachers need to use corresponding student number and employee number to register before using MOOC teaching system. After registration, they can $\log$ in with registered user ID and password.

Figure 5 and figure 6 respectively shows the client of students and teachers. We can see from figure 5 and figure 6 that student client displays student information, student client features include: video viewing, learning programs, teachers ' feedback, recently watched videos, assignment upload and forum links. Thus it can be seen that the system contains comprehensive functions, which include video selection, discussions \& exchanges, assignment submission, humanistic forum links and teacher feedback reminder. it has simple interface yet powerful features. Teacher client and student client allow video interaction with each other, teacher client also allows teaching information upload and simple process of uploaded information, it also allows teachers learning video recording experience from other teachers through the video library, the teacher client is also simple and practical.

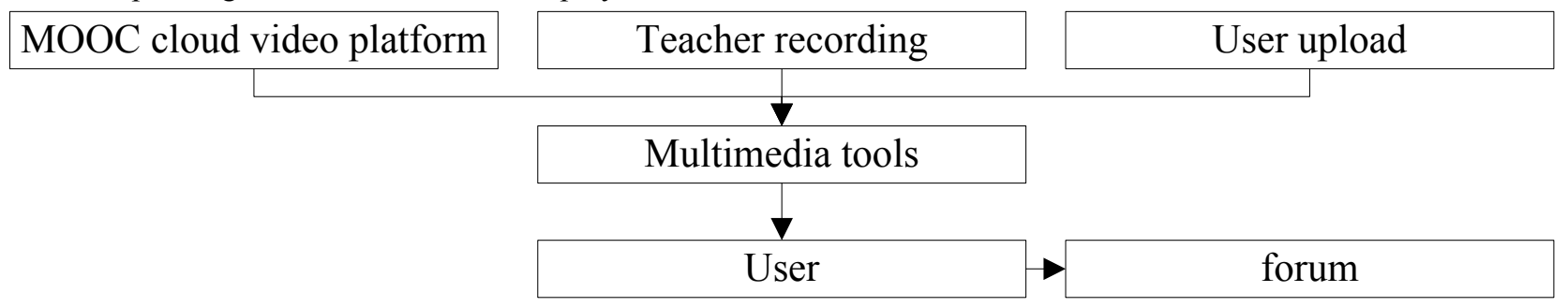

Figure 3. Diagram of Operation Mode of Multimedia MOOC System
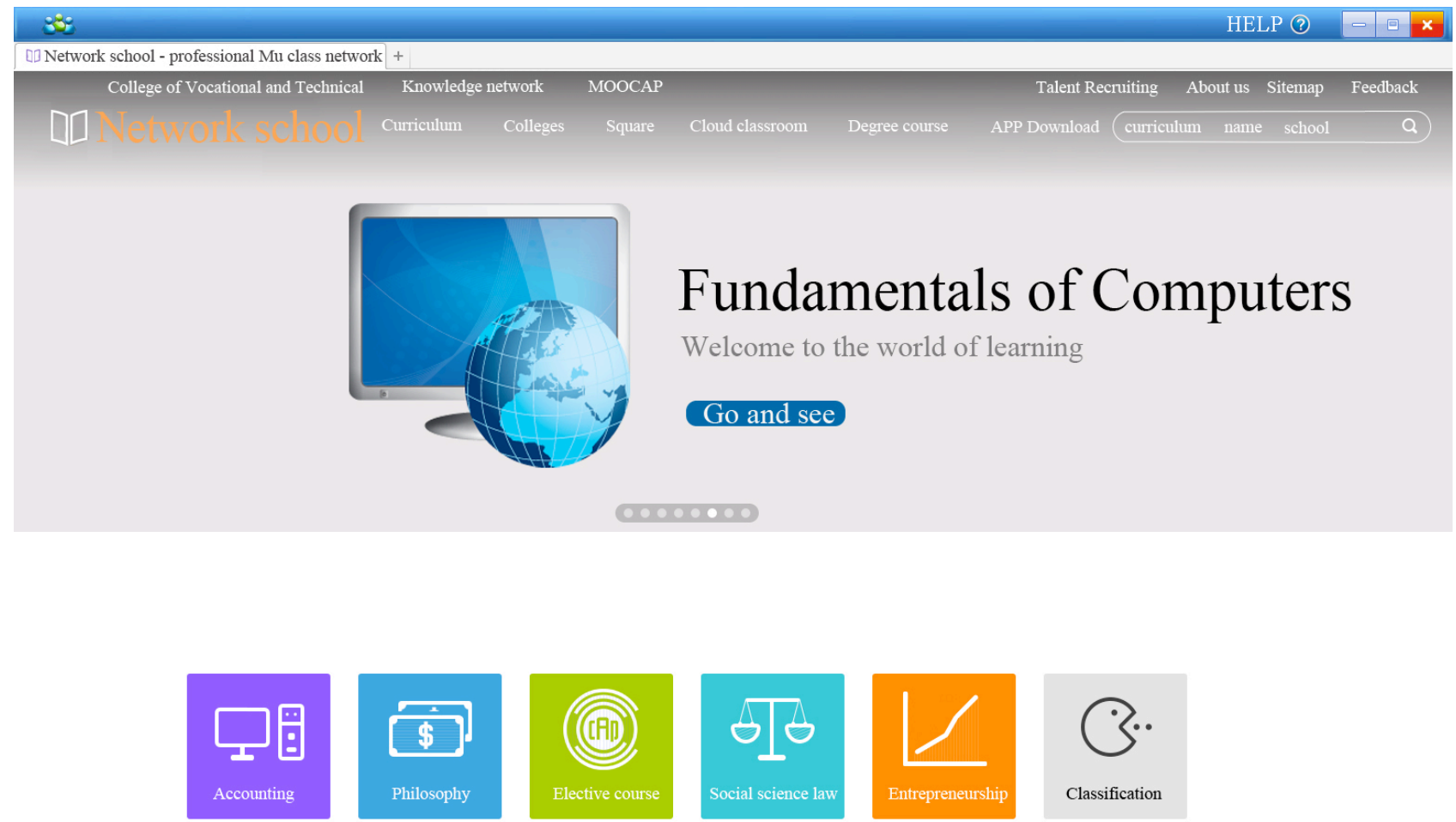

Figure 4. System Main Pages 


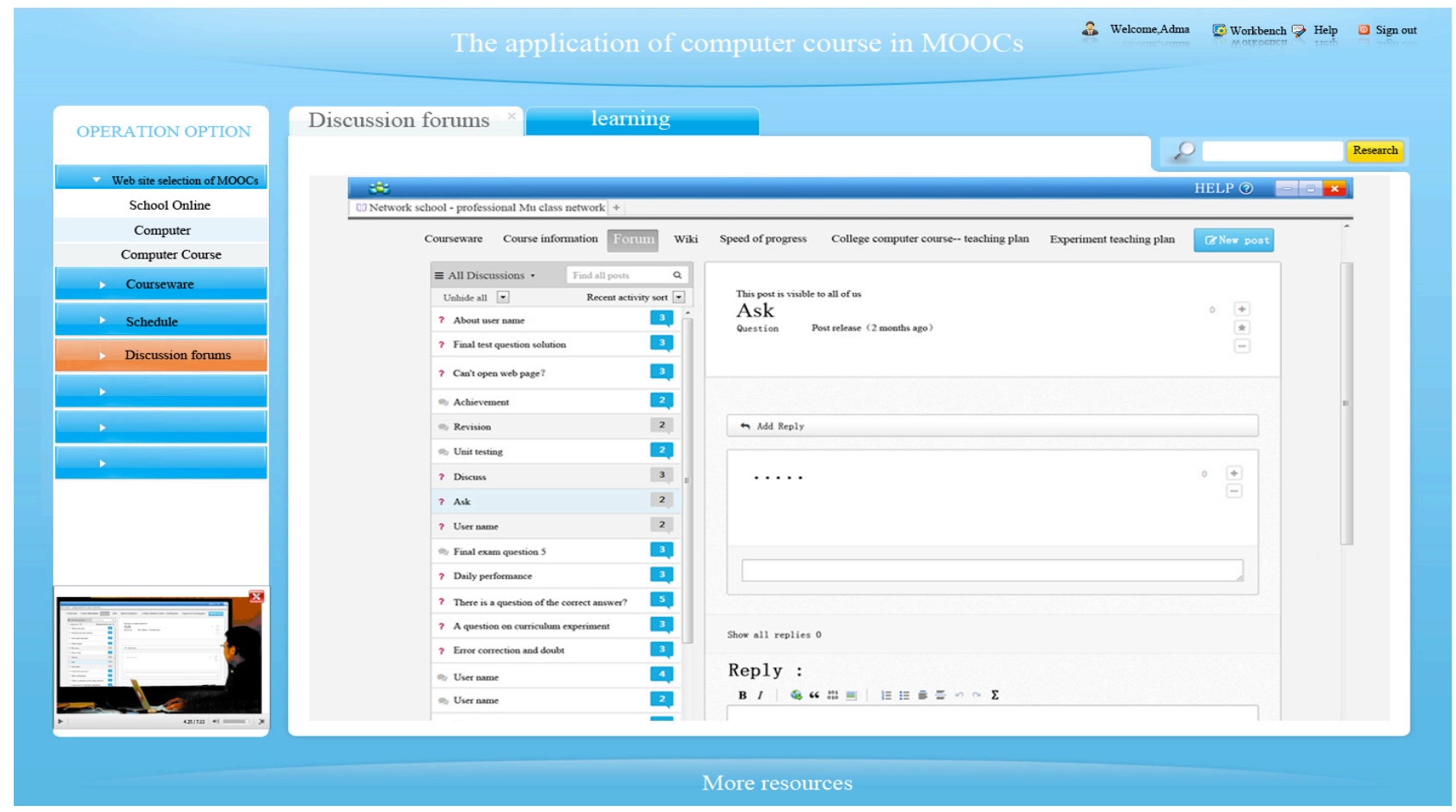

Figure 5. The Student Client

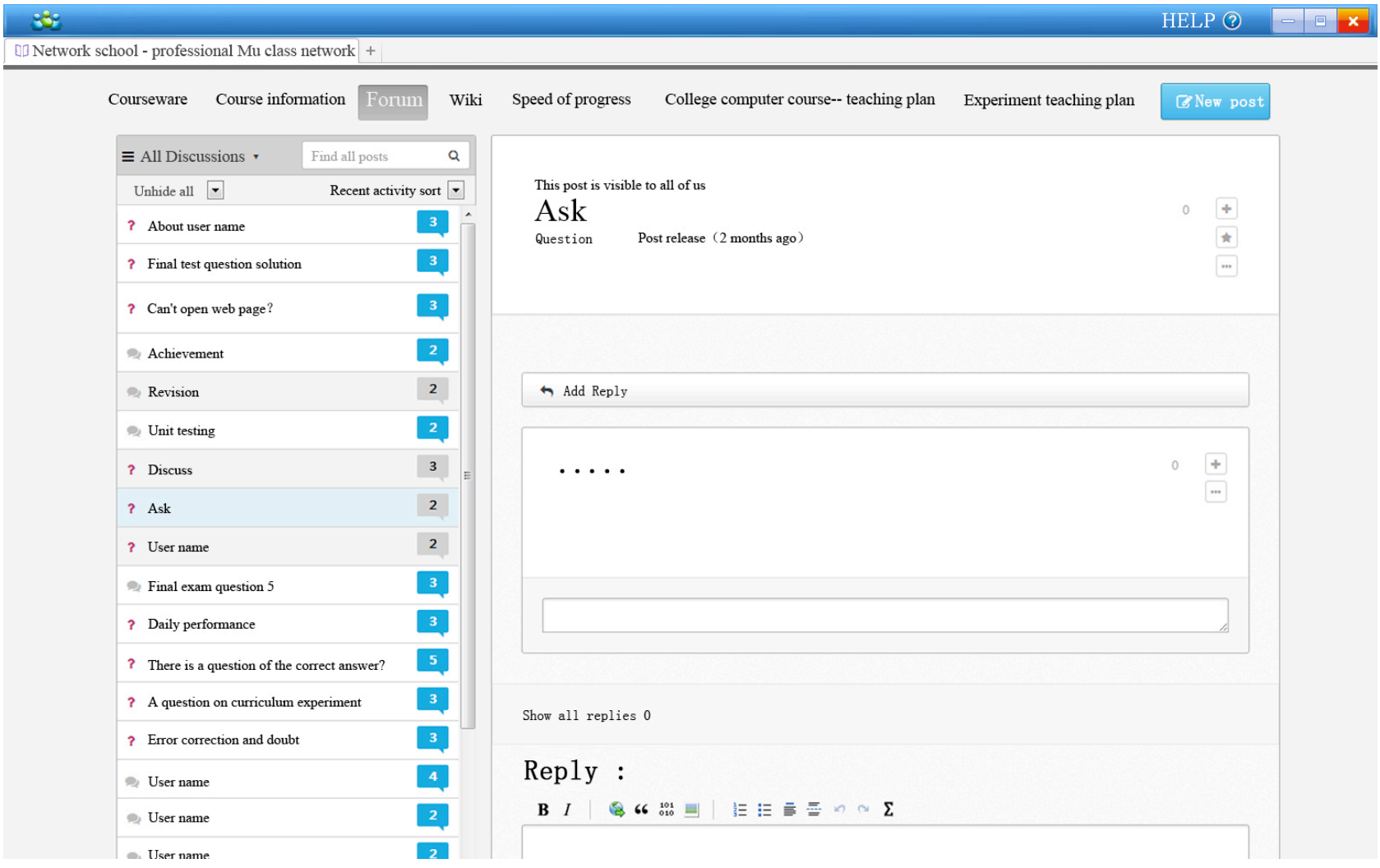

Figure 6. Interaction between Teachers and Students in MOOC Teaching System

\section{EXAMPLE ANALYSIS}

60 college students from Yiwu Industrial \& Commercial College in Zhejiang Province of China were selected, among which 30 students are in computer science major, the other 30 students are non-computer majors. 60 people were divided into 2 groups, group one is experimental group, of which 15 students are in computer major, the other 15 students are non-computer majors; group two is control group, in which computer and non-computer majors are 15 students respectively.

Group 1 used multimedia MOOC system to learn computer courses, its video resources came from videos recorded by well-known teachers, to guarantee scientific and effective experiment results, experiment took for 1 week, students can decide independently which teaching video to 
watch daily; group 2 used traditional computer teaching way, teaching by different of teachers daily, teaching time is the same with experiment group. At the end of the teaching, examination assessment and questionnaires were conducted.

\section{A. Analysis of test results}

After a week-long experiment of computer course, examination for members in two groups were conducted, their test scores are as follows:

We can see from table I that experimental group had better exam results than control group, more students in experimental group had higher scores, among which 27 students got scores above 80, 10 students got scores above 90; control group had 23 students with scores above 80,8 students with scores above 90. Experimental group had larger proportion of higher scores, this result showed that multimedia MOOC system had better effect than traditional teaching mode in computer teaching. Table 2 also shows that students in computer major generally had better scores than students in non-computer majors, which illustrates the fact that foundation for computer learning is very important, and individualized teaching method should be used in accordance with their aptitude in computer teaching to meet the needs of cultivation of different levels.

\section{B. Analysis of the questionnaire results}

An anonymous survey was conducted after a week-long experiment between the experimental group and control group. There were two questionnaire participants: the first kind is 7 computer teachers, the other kind is 60 students from the experiment. The survey questionnaire issued a total of 67 questionnaires, 67 were valid. Analysis of the survey results was conducted.
We can see from table II that majority of teachers were supportive for multimedia MOOC teaching system. Satisfaction in the simple interface of the system were highest, which means the system is relatively simple to operate. Teachers was not very satisfactory on the effectiveness of multimedia teaching and teaching experience, which showed that teachers could not fully adapt to the sudden change of teaching pattern, this requires related training for teachers. In General, teachers' acceptance for multimedia MOOC teaching system is relatively high, mainly because the multimedia MOOC teaching system relieved teachers from time limits enabling them to organize their work more rationally. Application of this system avoid impact by teachers' different status on the teaching quality. This system greatly reduced teacher's teaching workload, so that teachers can have more time to prepare for the course, thus improving the quality of course. But there is skepticism on the teaching and experience, to enable teachers to adapt to this system, some training and a certain break-in time adaptation is essential.

By analyzing table III, we can see that students are quite satisfactory with multimedia MOOC teaching system. They generally feel that the system can raise their interest in learning and learning efficiency. $80 \%$ of the students think that it has good operation which means it has a good design. Most of the students think that this system can enhance their interest in learning, this is mainly because students in information age have a great sense of curiosity and the ability to adapt to network and multimedia, they were enlightened on information teaching in their earlier stage, they have a strong interest in digital education and can adapt to multimedia teaching system more easily.

TABLE I.

Distribution OF TEST SCORES OF EXPERIMENTAL GROUP AND THE CONTROL GROUP

\begin{tabular}{lccccc}
\hline \multicolumn{1}{c}{ Score } & Below 60 & $\mathbf{6 0 - 7 0}$ & $\mathbf{7 0 - 8 0}$ & $\mathbf{8 0 - 9 0}$ & Above 90 \\
\hline Experimental group computer major & 0 & 0 & 0 & 9 & 6 \\
Experimental group non-computer majors & 0 & 0 & 3 & 8 & 4 \\
Control group computer major & 0 & 0 & 2 & 8 & 5 \\
Control group non-computer majors & 0 & 1 & 4 & 7 & 3 \\
\hline
\end{tabular}

TABLE II.

TEACHERS' APPLICATION STATISTICS

\begin{tabular}{lccc}
\hline & A (Yes) & B (No) & C (Unclear) \\
\hline Was this system convenient? & 4 & 1 & 2 \\
Was the system interface simple? & 6 & 0 & 1 \\
Was it effective? & 4 & 1 & 2 \\
Did it raise the teaching efficiency? & 3 & 1 & 3 \\
Was there a better experience compared with the traditional way? & 3 & 2 & 1 \\
\hline
\end{tabular}

TABLE III.

STUDENTS’ APPLICATION STATISTICS

\begin{tabular}{lccc}
\hline & A (Yes) & B (No) & C (Unclear) \\
\hline Was the teaching system interesting? & 40 & 8 & 12 \\
Was the system convenient and easy to operate? & 48 & 5 & 7 \\
Did this system improve learning efficiency? & 30 & 13 & 17 \\
Did this system help to enhance the learning interest? & 42 & 10 & 8 \\
\hline
\end{tabular}




\section{DISCUSSIONS}

Through observation of its teaching practice and application in computer course, multimedia MOOC teaching platform gained certain effects and inspired students ' interest in learning and improved their learning efficiency.

The main advantages of this platform are summarized as follows: first, the course is not limited by the time and geological locations. This teaching platform, by using internet and new multimedia MOOC system, enable teachers and students to decide on their own schedule as to when and where to communicate online or offline about the teaching contents, which is convenient and quick; second, this system, by taking advantage of big storage capacity, allows displaying learning contents in various ways, such as text, graphs, video, audio etc.. This display method combines context, sound, pictures together, making it more attractive to students and excites learning enthusiasm, also making the memory of knowledge last longer; third, multimedia MOOC teaching system not only allows unilateral video data upload, it also has corresponding feedback module, where students can post their problems encountered in their learning process in corresponding forum or QQ Group, teacher will answers them in the forum, this greatly increased the interaction level in the learning process, making learning more interesting and exciting students ' enthusiasm for learning; more importantly, it reduced the workload for teachers and enhanced teaching interactivity and convenience at the same time. (The platform is easy to operate, teachers only need to access the system via the Internet in the course of teaching, which significantly reduced the working load of teachers).

\section{CONCLUSIONS}

Multimedia MOOC teaching system can distribute educational resources more rationally through online open teaching. It promotes reform of traditional education, making teaching more effective. Taking application of multimedia MOOC teaching in the computer course as example, experimental group and control group were selected, by score analysis and questionnaire survey, we can conclude that the system has advantages such as: no time or geological location limits, less work load for teachers, higher learning interest and higher efficiency etc. However, this system also has some problems, this article summarized recommendations from students and teachers and presented improving measures such as improving system interaction level by using technology, upgrading the video recording and editing level, combining online and offline teaching for strengthening supervision of students independent learning etc.. Multimedia MOOC teaching allocates educational resources more rationally compared to traditional teaching methods. It offers a direction for educational reform.

\section{REFERENCES}

[1] Viswanathan R., "Teaching and Learning through MOOC," Frontiers of Language and Teaching, vol. 3, pp. 32-40, October 2012.

[2] Fan W.Q., "Massive Open Online Course (MOOC) Based on Connectivism and its Learning Support," Journal of Distance Education, vol. 30, no. 3, pp. 31-36, August 2012.

[3] [3] Knox J., "Digital culture clash: "massive" education in the Elearning and Digital Cultures MOOC," Distance Education, vol. 35, no. 2, pp. 164-177, January 2014. http://dx.doi.org/10.1080/ $\underline{01587919.2014 .917704}$

[4] Al-Atabi M., DeBoer J., "Teaching entrepreneurship using massive open online course (MOOC)," Technovation, vol. 34, no. 4, pp. 261-264, April 2014. http://dx.doi.org/10.1016/j.technovation. 2014.01.006

[5] Fidalgo Blanco Á., Sein-Echaluce Lacleta M.L., "García-Peñalvo F J. Methodological Approach and Technological Framework to break the current limitations of MOOC model," Journal of Universal Computer Science, vol. 21, no. 5, pp. 712-734, May 2015.

[6] DeBoer, J., Stump, G. S., Seaton, D., \& Breslow, L., "Diversity in MOOC students' backgrounds and behaviors in relationship to performance in 6.002 x," Proceedings of the Sixth Learning International Networks Consortium Conference, vol. 4, 2013.

[7] Ye H.W., Du X.J., "Development of Application-oriented Threelevel Instruction System of Public Computer Curriculum at Normal Universities - a Case Study at South China Normal University," Modern Educational Technology, vol. 19, no. 6, pp. 36, June 2009.

[8] Feng L.M., "Computer Teaching Based on Application-Oriented Talents Cultivation," Computer Software and Applications, vol. 16 no. 8, pp. 227-228, August 2013.

[9] Xu L.Z., "Study on Multimedia Teaching Resource Database Construction Based on Cloud Computing," The Computer Age, no. 6, pp. 48-50, July 2012.

[10] Zhu Y., Luo L.X., "Curriculum Teaching Design on EDX MOOC Platform and Application Analysis," Electronic World, no. 19, pp. 108-108, October 2014.

[11] Kellogg S., "Online learning: How to make a MOOC," Nature, vol. 499, no. 7458 , pp. 369-371, July 2013. http://dx.doi.org/10. 1038/nj7458-369a

\section{AUTHORS}

Zhenhua JI is a Lecturer of Yiwu Industrial and Commercial College, Yiwu 322000, Zhejiang, China. His research interests include Application of Computer and Safety Education. (jizhenhua1@yeah.net)

Submitted 29 March 2016. Published as resubmitted by the authors 10 May 2016. 